\title{
Fair, and still a sun lover: risk of gallstone formation
}

\author{
S Pavel, C T Thijs, V Potocky, P G Knipschild
}

\begin{abstract}
Study Objective-The aim was to evaluate the hypothesis that sunlight exposure leads to the development of gallstones in people with a sun sensitive skin.
\end{abstract}

Design and setting-This was a casecontrol study among 206 white patients referred for an ultrasound examination of the gallbladder. Sunlight exposure and skin sensitivity were retrospectively assessed by a structured questionnaire. The questionnaire was taken before the outcome of the ultrasound examination was known, so that the patients and the interviewers were blind to the outcome. The main outcome measure was gallstones in the gallbladder detected by ultrasound.

Main results -87 patients had gallstones (cases), 119 had none (controls). In subjects with a skin sensitive for sun (Fitzpatrick skin type I) a positive attitude to sunbathing was associated with a higher risk of gallstones than a negative attitude. In subjects with an insensitive skin (skin type IV) no association was found.

Conclusions-This study confirms a hypothesis which was based upon metabolic research. However it is too early to upgrade the first " $F$ " in the traditional adage that gallstone patients are "fair, fat, female, fertile and forty". Since both epidemiological and pathobiological evidence is scarce, the role of sun and/or (ultraviolet) light exposure and skin sensitivity in the aetiology of gallstones should be confirmed by further research.

f Epidemiol Community Health 1992; 46: 425-427

Gallstone sufferers are "fair, fat, fertile, forty, and female". These famous five F's ${ }^{1}$ have been downgraded as fallacies, "fair" even as plain falsehood. ${ }^{2}$ Nevertheless, metabolic research has suggested some clues to link skin colour to the risk of gallstone formation. One hypothesis says that activation of the pigmentary system of the skin (eg, by sun exposure) leads to increased levels of indolic melanin precursors in bile. These compounds can form a polymer network in the gallbladder that serves as a nucleus for gallstone formation. ${ }^{3}$ This hypothesis predicts that people with a sun sensitive skin are prone to gallstones when they endure intense exposure to sunlight. We evaluated this prediction in a case-control study.

\section{Methods}

Subjects were recruited from white men and women of Dutch nationality, aged 15-65 years, who were referred to a local hospital in The Netherlands for an ultrasound examination of the gallbladder. Among the 211 participants, the ultrasound examination showed 87 to have gallstones (cases). In the other 124 no gallstones could be detected in the gallbladder (controls). There were no male cases below age 40 years, and therefore five male controls below this age were excluded from the analysis, leaving 87 cases (13 men and 74 women) and 119 controls ( 24 men and 95 women).

All subjects were interviewed by trained interviewers, using a structured questionnaire. The interview took place before the ultrasound examination, thereby blinding the study subjects and the interviewer. Questions included body weight and height, number of pregnancies, skin reactions to sunlight, and sunbathing habits. Table I shows how a "sun attitude" score was composed, and how the subjects were classified according to skin sensitivity to sunlight (conforming to Fitzpatrick's classification of skin type ${ }^{4}$ ). Typically, people with skin type I are light skinned with red or blond hair, usually blue eyes, and very often with freckles. Sun attitude score was categorised by tertiles as "negative" (score 0-3), "indifferent" (score 4-6), and "positive" (score 7-11). Skin types II and III were combined because of the small numbers of subjects in these categories.

Relative risks of having gallstones were estimated by odds ratios in logistic regression analysis. $^{5}$

Confounding variables controlled for were sex, age, body mass index (weight divided by height squared), and number of pregnancies.

There were no statistically significant differences in the results between men and women. Therefore we present the results for men and women combined.

\section{Results}

Sun attitude was positively associated with gallstone risk, with a statistically significant doseeffect relation (table II, last column). A positive sun attitude was associated with a double risk of gallstones when compared to a negative sun attitude (relative risk $2 \cdot 1$ ). No association was found between skin type and gallstone risk when sun attitude was not taken into account (data not shown).

When the effect of sun attitude was considered for the skin types separately, the association was almost fully restricted to people with the most 
sensitive skin type (skin type I; table II). In this group the relative risk was $25 \cdot 6$ for a positive sun attitude compared to a negative one.

We wondered whether similar results would be obtained if we used only data on the question which we felt to be the best single indicator of sun exposure: "Do you love sunbathing?". The results showed the same pattern as the results on sun attitude. Among people with skin type I the relative risks of gallstones associated with loving sunbathing were 3.2 for "sometimes" ( $95 \%$ confidence interval $0.7-15.4)$, and 8.8 for "yes" (95\% confidence interval 1.7-45.9; compared to "no"; test for trend $p=0.003$, one sided). In other skin types no clear association between loving sunbathing and risk of gallstones was found (data not shown).

\section{Discussion}

The major weakness of this study relates to the quality of the measurements. Exposure to sunlight was only measured by proxy via "sun attitude". This approach has already been used in papers investigating the relation between sunlight exposure and malignant melanoma. ${ }^{67}$ Sensitivity to sunlight was measured with one single subjective rating by the participant. It is questionable whether actual sun exposure and skin sensitivity can be adequately separated from each other in

Table I Sun attitude score ( sum of the component scores) and skin sensitivity to sunlight (skin type classification)

Table II Number of cases and controls (percentages in brackets), and relative risk of gallstones $(R R)$ for sun attitude, separately for the skin types, and overall (last column), with $95 \%$ confidence intervals $(95 \%$ CI).

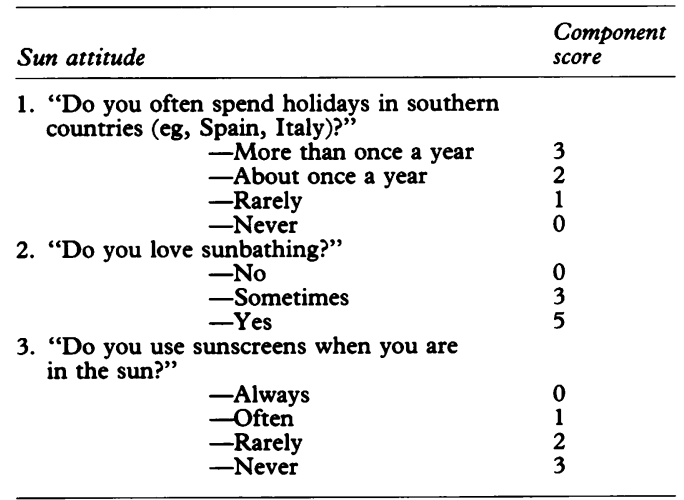

Skin sensitivity to sunlight Skin type

"What is your skin reaction after long sunbathing when you do not use sunscreens? -Always burn -Often tan, sometimes bur -Always tan
I II IV -Often burn, sometimes tan this way. Moreover, in patients presenting with gastrointestinal symptoms, gallstones have probably formed many years before. ${ }^{8}$ With our short questionnaire we could not specify sun exposure in several periods in the past to relate to a limited risk period. The resulting mismatch of time of exposure and the risk period of gallstones formation may therefore lead to underestimation of the effect, ${ }^{9}$ and it further hampers the separation of actual sun exposure and skin sensitivity. In view of these limitations, it is surprising that an effect of sun exposure depending on skin sensitivity could be confirmed.

Nevertheless, we think that the findings cannot easily be attributed to biases in the study. Selection bias (eg, due to earlier detection of gallstones in fair patients with vague gastrointestinal symptoms) was precluded by selection of cases and controls with the same indications for referral for ultrasound, and before the diagnosis was known. Information bias (eg, due to prior expectation of the interviewers who knew of the hypothesis) was avoided by blinding the patients and the interviewers with respect to the diagnosis. Main potential confounding variables (age, sex, pregnancy, and body mass) were controlled for in the analysis. Confounding by other risk factors for gallstones that may be associated with sun attitude and that were not controlled for (eg, alcohol abstinence) is still possible. However it is unlikely that such factors are also related to skin type. Therefore confounding by such factors can hardly explain the dependence of the effect of sun attitude on skin type. For these reasons we believe that the result of our study could be more than an artefact.

The hypothesis engendering the present study was based on the identification of indolic melanin precursors in bile of a patient with mixed gallstones, and in the brown pigment gallstone of another patient. ${ }^{3}$ The results of the present study, however, are also compatible with another mechanism: augmented photoisomerisation of unconjugated bilirubin by light exposure, enhancing the formation of (black) pigment stones. ${ }^{10}$ In the present study, we had no data on stone type. Most gallstone patients in The Netherlands have cholesterol stones. The chemical composition of pigmented centres of cholesterol gallstones has been found to be quantitatively different from that of black pigment

\begin{tabular}{|c|c|c|c|c|c|c|c|c|}
\hline \multirow[b]{3}{*}{ Sun attitude } & \multicolumn{8}{|l|}{ Skin type } \\
\hline & \multicolumn{2}{|l|}{$I$} & \multicolumn{2}{|c|}{$I I$ and III } & \multicolumn{2}{|l|}{$I V$} & \multicolumn{2}{|l|}{ All } \\
\hline & Cases & Controls & Cases & Controls & Cases & Controls & Cases & Controls \\
\hline $\begin{array}{l}\text { Negative } \\
\text { Indifferent } \\
\text { Positive }\end{array}$ & $\begin{array}{r}8(32) \\
10(40) \\
7(28)\end{array}$ & $\begin{array}{r}24(59) \\
13(32) \\
4(10)\end{array}$ & $\begin{array}{l}10(29) \\
10(29) \\
14(41)\end{array}$ & $\begin{array}{l}12(26) \\
17(37) \\
17(37)\end{array}$ & $\begin{array}{r}7(25) \\
9(32) \\
12(43)\end{array}$ & $\begin{array}{r}10(31) \\
6(19) \\
16(50)\end{array}$ & $\begin{array}{l}25(29) \\
29(33) \\
33(38)\end{array}$ & $\begin{array}{l}46(39) \\
36(30) \\
37(31)\end{array}$ \\
\hline \multirow[t]{2}{*}{ Total } & $25(100)$ & $41(100)$ & $34(100)$ & $46(100)$ & $28(100)$ & $32(100)$ & $87(100)$ & $119(100)$ \\
\hline & \multicolumn{2}{|c|}{$R R(95 \% C I)^{\mathrm{a}}$} & \multicolumn{2}{|c|}{$R R(95 \% C I)^{\mathrm{a}}$} & \multicolumn{2}{|c|}{$R R(95 \% C I)^{\mathrm{a}}$} & \multicolumn{2}{|c|}{$R R(95 \% C I)^{\mathrm{b}}$} \\
\hline $\begin{array}{l}\text { Negative } \\
\text { Indifferent } \\
\text { Positive }\end{array}$ & $\begin{array}{r}1 \cdot 0 \\
3 \cdot 4 \\
25 \cdot 6\end{array}$ & $\begin{array}{l}\text { (reference) } \\
(0 \cdot 8-14 \cdot 6) \\
(3 \cdot 2-205)\end{array}$ & $\begin{array}{l}1.0 \\
0.7 \\
1.7\end{array}$ & $\begin{array}{l}\text { (reference) } \\
(0 \cdot 2-2 \cdot 7) \\
(0 \cdot 5-6 \cdot 2)\end{array}$ & $\begin{array}{l}1 \cdot 0 \\
2 \cdot 3 \\
1 \cdot 8\end{array}$ & $\begin{array}{l}\text { (reference) } \\
(0 \cdot 5-11 \cdot 0) \\
(0 \cdot 4-7 \cdot 8)\end{array}$ & $\begin{array}{l}1 \cdot 0 \\
1.5 \\
2 \cdot 1\end{array}$ & $\begin{array}{l}\text { (reference) } \\
(0 \cdot 7-3 \cdot 2) \\
(1 \cdot 0-4 \cdot 5)\end{array}$ \\
\hline Test for trend (one sided) & \multicolumn{2}{|c|}{$p=0.001$} & \multicolumn{2}{|c|}{$p=0.19$} & \multicolumn{2}{|c|}{$p=0.21$} & \multicolumn{2}{|c|}{$p=0.028$} \\
\hline
\end{tabular}

a Results of logistic regression analysis for each skin type separately, controlling for sex, age, body mass and number of pregnancies.

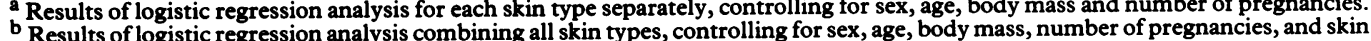

Results of logistic regression analysis combining all skin types, controlling for sex, age, body mass
type.

cTest for trend of logarithm of the odds ratio over categories of sun attitude (coded 1, 2, 3). Note: Test of the dependence on skin type of the association between sun attitude and the risk of gallstones (assessed by testing for the statistical interaction between sun attitude score (as an interval variable) and skin type (coded 1 to 4): maximum likelihood ratio 5.25 $(1 \mathrm{df}), \mathrm{p}=0.022$. Test of the joint contribution of sun attitude and skin type (including interaction): maximum likelihood ratio 10.58 $(3 \mathrm{df}), \mathrm{p}=0.014$. Coefficients (standard errors): sun attitude score $0.4886(0 \cdot 1700)$, skin type 0.6174 (0.3139), interaction -0.1277
$(0.05693)$. 
stones, suggesting that cholesterol stones do not form on a pigment stone nidus. ${ }^{11}$ However, this certainly does not rule out the possibility that the small amount of non-cholesterol material in cholesterol stone centres is involved in stone nidation. Therefore it remains possible that sun (or light) exposure is also involved in the pathogenesis of cholesterol gallstones.

Thus far the evidence is sparse. Furthermore, only a few steps in the possible mechanisms are known. It seems too early to upgrade the most intriguing of the five F's, the fair complexion of the gallstone patient. It seems that the influence of skin colour in whites should not be considered without attention to sun and/or light exposure. Further epidemiological research on this topic should aim at more accurate measurement of sun exposure (and possibly light and sun beds as well), at closer timing with respect to the aetiological moment of gallstone formation, and at distinguishing between pigment and cholesterol gallstones.
1 Sherlock S. Diseases of the liver and biliary system, 3rd ed. Oxford: Blackwell Scientific Publications, 1963: 641.

2 Facts and fallacies about gall stones (Editorial). BMF 1981; 283: 171 .

3 Pavel $\mathrm{S}$. A new possible pathogenesis of some gallstones. Med Hypotheses 1984; 14: 285-92.

4 Fitzpatrick TB. Soleil et peau. f Med Esthet 1975; 2: 33-6.

5 Kleinbaum DG, Kupper LL, Morgenstein H. Epidemiologic research. Principles and quantitative methods. London: Lifetime Learning Publications, 1982

6 Lew RA, Sober AJ, Cook N, Marvell R, Fitzpatrick TB. Sun exposure habits in patients with cutaneous melanoma. A case control study. F Dermatol Surg Oncol 1983; 9: 981-6.

7 Elwood JM, Gallagher RP, Hill GB, Spinelli JJ, Pearson JCG, Threlfall W. Pigmentation on skin reaction to sun as risk factor for cutaneous melanoma: Western Canada melanoma study. BMF 1984; 288: 99-102.

8 Mok HY, Druffel ER, Rampone WM. Chronology of cholelithiasis, dating gallstones from atmospheric radiocarbon produced by nuclear bomb explosions. $N$ Engl f Med 1986; 314: 1075-7.

9 Thijs CT, Knipschild PG, Leffers P. Pregnancy and gallstone disease - an empirical demonstration of the importance of specification of risk periods. Am $\mathcal{F}$ Epidemiol 1991; 134: 186-95.

10 Ostrow JD. The etiology of pigment gallstones. Hepatology 1984; 4 (suppl): 215-22s.

11 Malet PF, Williamson CE, Trotman BW, Soloway RD. Composition of pigmented centers of cholesterol gallstones. Hepatology 1986; 6: 477-81. 